\title{
MA Defence: "How Social Media Users Negotiate Self-Censorship in the Online Public Sphere" By Jes Scott
}

\section{Sibo Chen}

School of Communication

Simon Fraser University

Our dear colleague, Jes Scott, will defend her MA Thesis on Friday, August 21st, 2015 (10:00-12:00)

at Harbour Centre, Room 1520. Here is the abstract of her thesis "How Social Media Users Negotiate Self-Censorship in the Online Public Sphere":

\begin{abstract}
Research about the public sphere and social media often focus on what is being posted, rather than examining what is being omitted or why. The aim of this research is to explore this gap by providing ethnographic, qualitative research on how social media users negotiate self-censorship while engaging in the online public sphere.
\end{abstract}

Keywords: Social media; ethnography; public sphere; self-censorship 